Artigos

\title{
O ensino teórico-prático durante a graduação em medicina: superando limitações
}

\author{
Edevard José de Araujo ${ }^{3}$, Igor Kunze Rodrigues ${ }^{1}$, Allan Jefferson Shollemberg", Aline Caramori , Bruna \\ Souza Marques ${ }^{2}$, Bruno Felipe Carvalho ${ }^{2}$, Giseli Duarte ${ }^{2}$, Hattos Paulo Mendes Soares ${ }^{2}$, Eduardo Soares Maia \\ Vieira de Souza ${ }^{3}$, Getúlio Rodrigues de Oliveira Filho ${ }^{3}$, Gilberto Vaz Teixeira ${ }^{3}$,Jorge Bins Ely ${ }^{3}$, Zulmar \\ Antônio Accioli de Vasconcellos ${ }^{3}$
}

\begin{abstract}
1-Estudante de doutorado do Programa de Pós-graduação em Ciências Médicas, Centro de Ciências da Saúde, Universidade Federal de Santa Catarina (UFSC), Campus Reitor João David Ferreira Lima, Florianópolis, Brasil.

2-Estudante do Curso de Graduação em Medicina (monitor do Laboratório de Técnica Operatória e Cirurgia Experimental), Centro de Ciências da Saúde, Universidade Federal de Santa Catarina (UFSC), Campus Reitor João David Ferreira Lima, Florianópolis, Brasil.

3-Professor do Departamento de Cirurgia, Centro de Ciências da Saúde, Universidade Federal de Santa Catarina (UFSC), Campus Reitor João David Ferreira Lima, Florianópolis, Brasil.
\end{abstract}

Autor para correspondência: Edevard José de Araújo. E-mail: dearaujoej@gmail.com $\mathrm{O}$ autor declara não ter conflitos de interesse em relação a esta publicação. Submetido em 16/10/19; aceito para publicação em 14/11/19

DOI: https://doi.org/10.32963/bcmufsc.v5i5.3822

Indexadores: Cirurgia geral; Cirurgia; Educação médica; Faculdades de medicina; Hospitais de ensino.

No período de graduação, os estudantes são estimulados a participar de atividades teóricas e práticas que enriqueçam e aperfeiçoem sua formação médica. As diretrizes curriculares apontam que é fundamental ao médico ter uma formação básica e geral, treinamento em todos os níveis de atenção à saúde e elevada formação ética e humanista, apresentando competência técnica para exercer a profissão1.

$O$ processo de ensino na medicina, principalmente nas áreas cirúrgicas, ocorre pela observação do ato cirúrgico e pela participação direta do estudante, realizado, entre outros métodos, através de tentativa e erro2. 0 Laboratório de Técnica Operatória e Cirurgia Experimental da Universidade Federal de Santa Catarina (TOCE - UFSC) tem como objetivo 0 aprimoramento da técnica dos diversos procedimentos cirúrgicos na graduação médica, sugerindo um método de fixação e aplicação do conhecimento teórico apresentado em sala de aula.
Os professores e monitores da disciplina acreditam no treinamento prático por meio de simulação, que recria uma experiência da situação real sem expor pacientes a riscos associados aos procedimentos. 0 ensino prático de procedimentos cirúrgicos encontra algumas limitações, destacando-se duas principais: a restrição ao uso de animais e 0 alto custo de materiais substitutivos. Além disso, não há investimentos diretos para substituição do material biológico. Por sua vez, a solução que o TOCE - UFSC teve foi de criar substitutivos próprios e o custeio, considerando as limitações financeiras, utilizando materiais sintéticos, associados ou não a materiais biológicos. Hoje, o Laboratório de Técnica Operatória conta com:

1) Treinamento de sutura em camada de etil vinil acetato (EVA) (Figura 1a), posteriormente, complementação da técnica utilizando língua bovina (Figura 1b).

2) Drenagem de tórax, utilizando hemitórax de costela porcina coberto por EVA e fixado em manequim próprio para realização do procedimento (Figura 2a). 

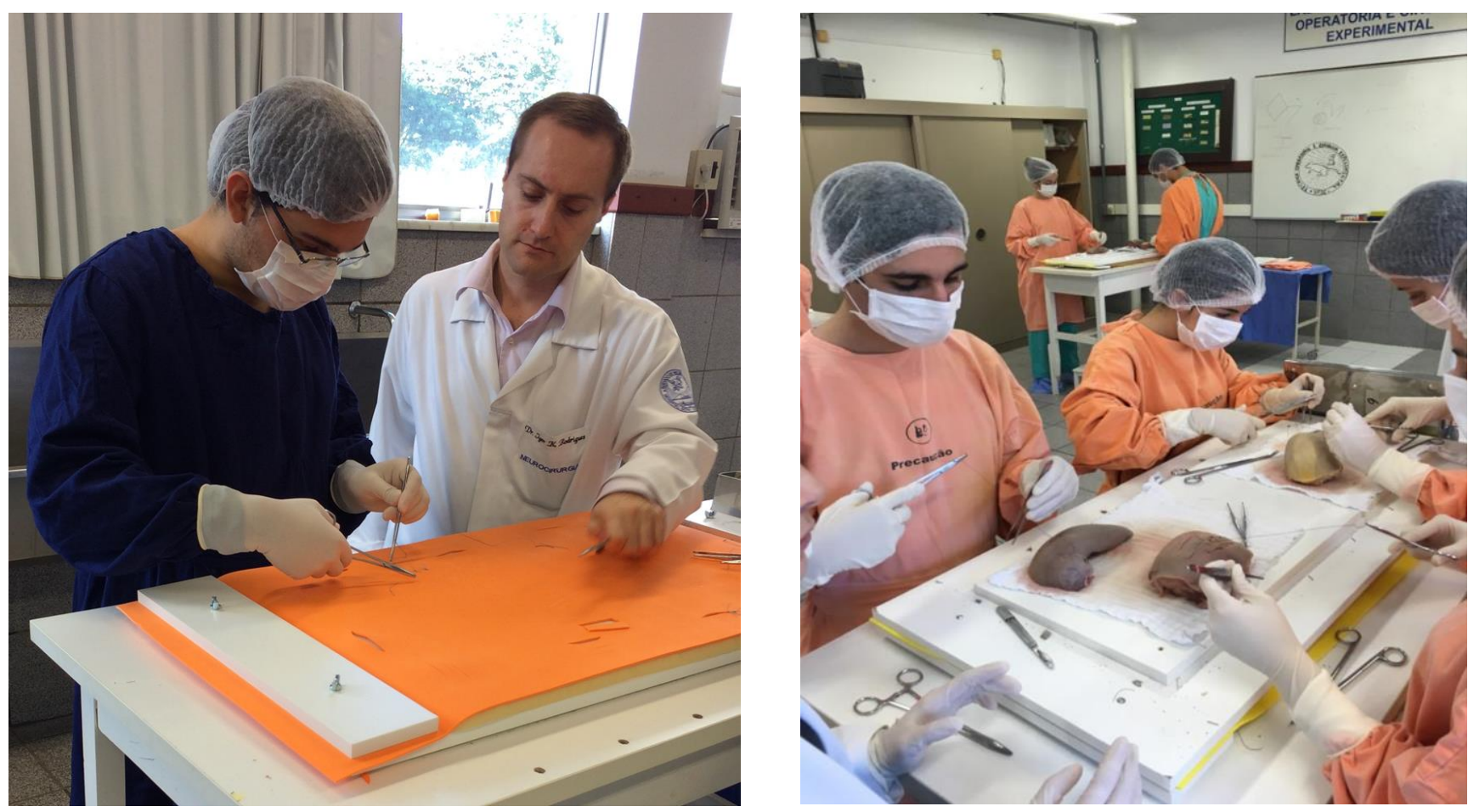

Figura 1.a) Treinamento de sutura em camada de etil vinil acetato (EVA). b) Treinamento de sutura em língua bovina.
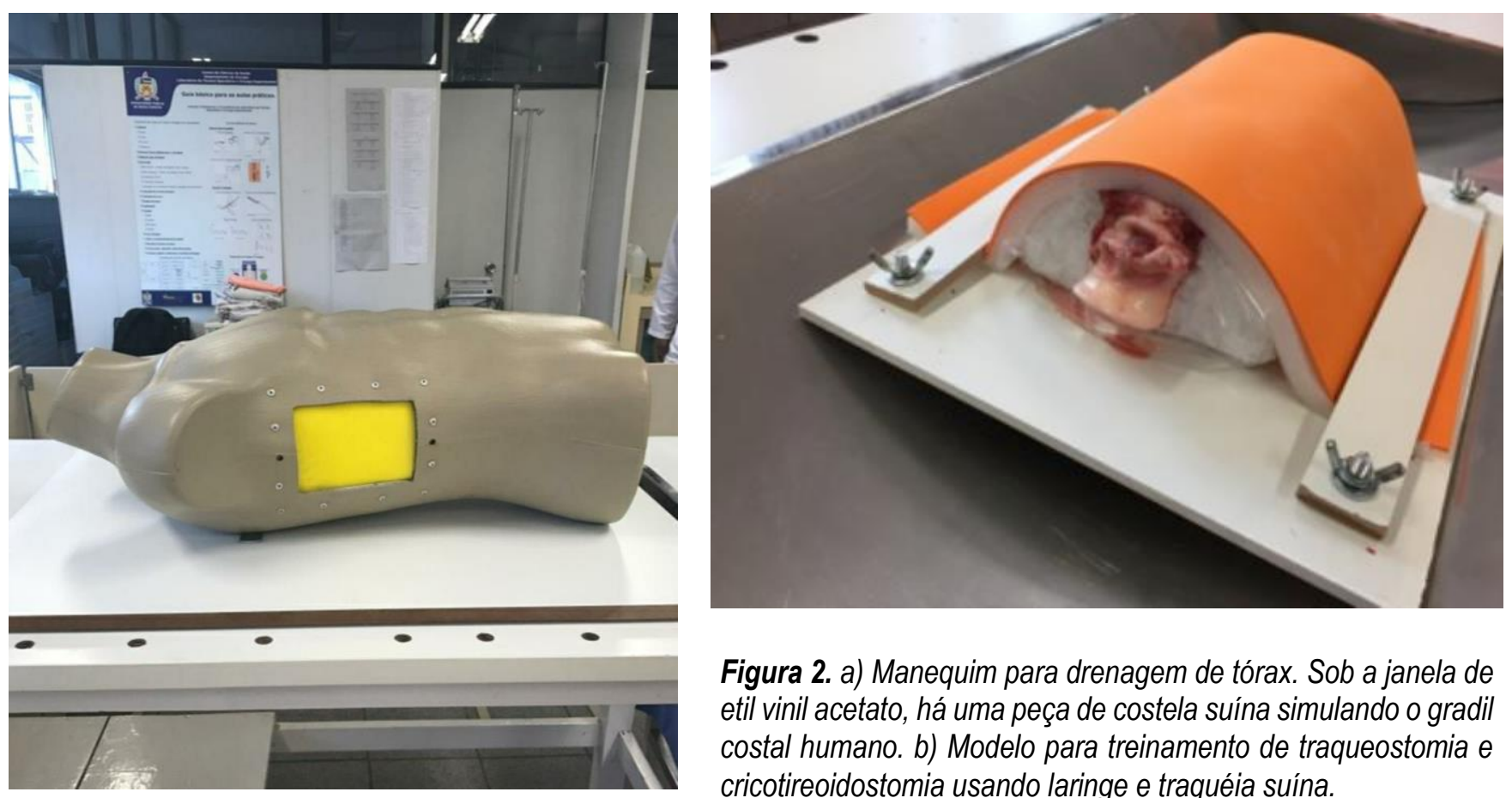

Figura 2. a) Manequim para drenagem de tórax. Sob a janela de etil vinil acetato, há uma peça de costela suína simulando o gradil costal humano. b) Modelo para treinamento de traqueostomia e cricotireoidostomia usando laringe e traquéia suína.

3) Cricotireoidostomia e traqueostomia utilizando laringe e traqueia suína coberto por uma camada de EVA e 0 conjunto fixado em molde plástico confeccionado através de impressão 3D (Figura 2b).

4) Drenagem de abscesso com protótipo idealizado e confeccionado pela própria equipe do TOCE - UFSC (Figura 3). Sob a camada de EVA, uma bolsa de borracha contendo líquido de consistência pastosa simula a anatomia de um abscesso. 


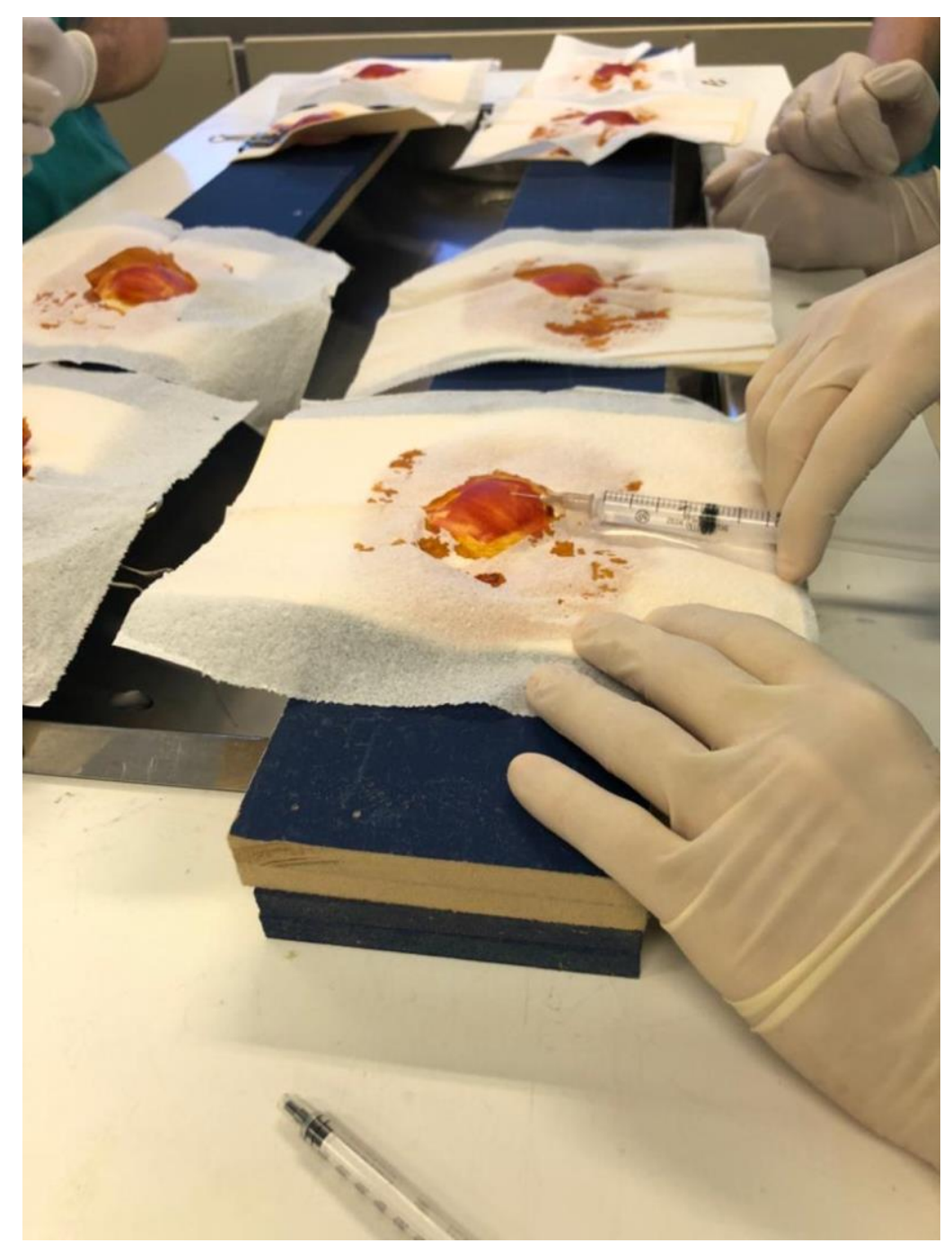

Figura 3. Modelo para treinamento de drenagem de abscesso

Segundo as Diretrizes Curriculares Nacionais do Curso de Graduação em Medicina do Ministério da Educação (MEC), o estudante deve saber realizar procedimentos clínicos e cirúrgicos necessários para 0 atendimento ambulatorial e de urgências e emergências.

A adaptação tem uma boa receptividade entre os estudantes, de forma que os conteúdos teóricos são abordados novamente, a orientação direta por professores e monitores facilita a visualização da técnica cirúrgica, e possibilita a correção individualizada de técnicas erroneamente compreendidas.

Embora estes modelos ainda sejam restritos ao Laboratório do TOCE - UFSC, este treinamento em modelos alternativos reflete ganhos ao graduando, à Universidade e à população. Tem custo reduzido e respeito aos princípios éticos, é seguro e de fácil reprodução, tentando simular os aspectos e as técnicas encontradas no ato cirúrgico realizado no ser humano.

\section{Referências}

1. Purim KS. Oficina de cirurgia cutânea. Rev Col Bras Cir. 2010;37(4):303-5

2. Reichel JL, Peirson RP, Berg D. Teaching and evaluation of surgical skills in dermatology: Results of a survey. Arch Dermatol. 2004;140(11):1365-9.

3. Purim KSM, Santos LDS, Murara GT, Maluf EMCP, Fernandes JW, Skinovsky J. Avaliação de treinamento cirúrgico na graduação de medicina. Rev. Col. Bras. Cir., 2013; 40(2): 152-6. 